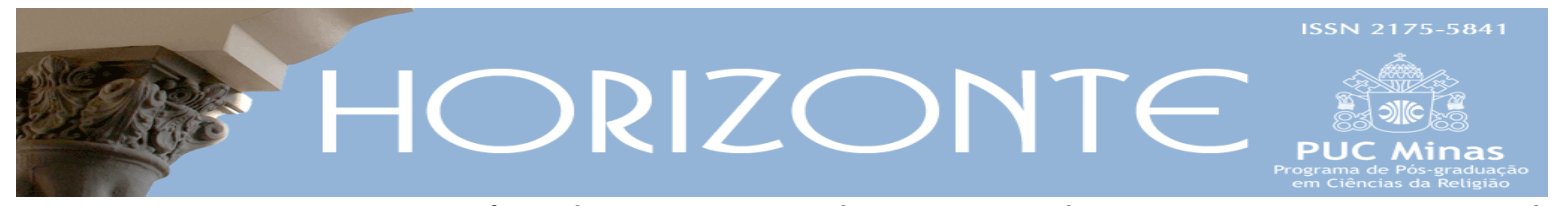

Dossiê: Islamismo: religião e cultura - Artigo original (C) $\odot \Theta \Theta$

DOI - 10.5752/P.2175-5841.2015v13n38p750

\title{
A nação hindu e o outro muçulmano na obra de V. D. Savarkar
}

\author{
Hindu nation and its muslim other in the work of V. D. Savarkar
}

Mirian Santos Ribeiro de Oliveira*

\begin{abstract}
Resumo
Entre as dinâmicas associadas a encontros interculturais, encontra-se a de (re-) elaboração de universos simbólicos por grupos sociais participantes de relações de alteridade. Em se tratando de relações de dominação imperial, entre os séculos 18 e 20, na Ásia, tal dinâmica envolveu a reinterpretação de universos simbólicos preexistentes, como os religiosos, bem como a criação de novos modos de organização simbólica da vida em sociedade, como as comunidades nacionais. Este artigo se concentra na análise da construção de um universo simbólico nacional-religioso em um contexto fortemente influenciado por relações de alteridade. Trata-se do discurso sobre a nação hindu e seu outro muçulmano, elaborado nas primeiras décadas do século 20, no subcontinente indiano, por um ideólogo nacionalista hindu, V. D. Savarkar. Adota-se como referencial teórico a fenomenologia, em sua vertente sociológica, e procede-se à análise do conteúdo da fonte primária Hindutva: Who is a Hindu? Argumenta-se que o ideólogo nacionalista hindu formulou uma retórica da aniquilação, em que o outro da nação hindu, o muçulmano, é inferiorizado por meio das estratégias de: exagero seletivo de características atribuídas ao muçulmano; transferência de definições socialmente negativas ao outro.
\end{abstract}

Palavras-chave: Nacionalismo religioso; Relações de alteridade; Hinduísmo; Islã; Índia britânica.

\begin{abstract}
Intercultural encounters generally imply dynamics of (re-)elaboration of symbolic universes by the social groups affected. Imperial domination of Asia, from the 18th to the 20th century, furthered the reinterpretation of existing symbolic universes, such as religious communities, as well as the creation of new modes of symbolic organization of social life, as national communities. This paper analyzes the construction of a religious-nationalist symbolic universe in a context strongly influenced by otherness. We consider the discourse on Hindu nation and its Muslim other, by V.D. Savarkar, a Hindu nationalist ideologue that was written in the early decades of the 20th century. We adopt phenomenology as theoretical framework and undertake content analysis of a primary source - Hindutva: Who is a Hindu? We argue that the Hindu nationalist ideologue elaborated a rhetoric of annihilation, in which the other of Hindu nation, the Muslim, is depicted as inferior through a double strategy: selective exaggeration of characteristics attributed to the Muslim; transfer of socially negative definitions to the other.
\end{abstract}

Keywords: Religious nationalism; Otherness; Hinduism; Islam; British India.

\footnotetext{
Artigo recebido em 08 abr. 2015 e aprovado em 23 de junho de 2015.

* Doutora em Sociologia (USP). Trabalha na Universidade Federal da Integração Latino-Americana (UNILA). País de origem: Brasil. E-mail: miriansroliveira@gmail.com.
} 


\section{Introdução}

Para a abordagem fenomenológica, a natureza localizada e específica da consciência da vida cotidiana implica a construção de universos simbólicos diferentes por grupos culturais distintos. Dessa forma, encontros interculturais podem ser marcados por choques entre universos simbólicos particulares e, portanto, estimular a criação e/ou utilização de mecanismos de conservação desses "corpos de tradição teórica que integram diferentes áreas de significação e abrangem a ordem institucional em uma totalidade simbólica” (BERGER; LUCKMANN, 2003, p. 131). O primeiro desses mecanismos, a terapêutica, consiste num esforço de legitimação positiva do universo simbólico do grupo social que se sente ameaçado pela presença de uma concepção de mundo estranha. Tal ameaça se refere tanto à possibilidade de perda de alguns de seus membros, atraídos pela visão de mundo do grupo externo, como de questionamento de seu modo de vida (e das representações simbólicas associadas a tal modo de vida). A fim de inibir a adesão de seus participantes ao universo simbólico do outro, o grupo interno busca reforçar a validade e a veracidade do conhecimento teórico formulado no interior da coletividade. Ao mesmo tempo, os elementos discordantes da concepção de mundo do outro são caracterizados como desvios a serem combatidos por estratégias que intentam garantir a permanência dos indivíduos no grupo social de origem.

O segundo mecanismo de conservação do universo simbólico de um grupo social participante de um encontro intercultural é a aniquilação. Trata-se de legitimação negativa, ou seja, da negação da "realidade de qualquer fenômeno ou interpretação de fenômenos que não se ajustam” no universo simbólico considerado (BERGER; LUCKMANN, 2003, p. 155). Tal negação pode ser realizada de duas maneiras: a) atribuição de status ontológico inferior à concepção de mundo do grupo externo, a partir de então menosprezada por também ser considerada dotada de um status cognoscitivo inferior; b) incorporação e tradução 
de elementos da concepção de mundo discordante ao universo simbólico do grupo interno, fazendo com que a negação deste universo simbólico, realizada pelo outro, passe a representar, em última instância, sua afirmação. A possibilidade de transformação do conhecimento teórico então produzido em práticas violentas contra o grupo externo - como nos casos de conflitos étnicos, por exemplo depende principalmente de recursos de poder disponíveis aos grupos em confronto, segundo Berger e Luckmann (2003).

Este artigo se concentra na análise do mecanismo de aniquilação, criado e fortalecido em contextos marcados por encontros interculturais. De modo mais específico, focaliza a primeira maneira de negação da concepção de mundo do outro - a atribuição de status ontológico e cognoscitivo inferior ao grupo externo. Para tanto, analisa a formulação de uma retórica da aniquilação por um ideólogo nacionalista hindu, V. D. Savarkar, considerando dois recursos retóricos frequentes no mecanismo de conservação do universo simbólico em questão: "o exagero seletivo de certos aspectos do fenômeno desafiador e a transferência ao tal fenômeno de definições socialmente negativas" (USARSKI, 2001, p. 92). Na próxima seção, apresenta-se brevemente o contexto de formulação do discurso de Savarkar sobre a nação hindu. Em seguida, analisa-se o discurso sobre o universo simbólico do grupo interno. Por fim, examina-se a retórica de aniquilação elaborada pelo ideólogo nacionalista hindu.

\section{Contexto de formulação do discurso sobre a nação hindu}

Antes de proceder à análise, propriamente dita, faz-se necessário caracterizar brevemente o contexto em que Savarkar formulou seu discurso sobre a nação hindu e, em decorrência disso, o discurso sobre os outros, os grupos externos considerados ameaçadores à própria existência de tal nação. Vinayak Damodar Savarkar (1883-1966) recebeu uma educação tradicional de castas altas, uma vez que pertencia a uma família brâmane do Maharashtra. Por outro lado, foi 
educado em moldes ocidentais, ao ingressar no sistema educacional da então colônia britânica, por meio de migrações internas - estudou no Fergusson College, em Pune, nos primeiros anos do século 20 e, em 1904, mudou-se para Bombaim com o intuito de cursar Direito -, bem como ao emigrar para a Grã-Bretanha, em virtude do recebimento de uma bolsa para qualificação profissional na metrópole, onde viveu entre 1906 e 1910. Participou ativamente dos processos de independência da Índia britânica, por meio do ativismo revolucionário que o levou à prisão, em 1910, bem como de atividades políticas formais ao liderar, no interior do Congresso Nacional Indiano, 1 o partido político Grande Associação Hindu2, em finais da década de 1920, como lembram Bhatt (2001) e Jaffrelot (2007).

O que se deseja ressaltar aqui é que Savarkar viveu e escreveu num período marcado pela intensificação e diversificação de processos de (re)construção de universos simbólicos no subcontinente indiano. $\mathrm{O}$ encontro intercultural entre britânicos e indianos, caracterizado por relações de poder assimétrico entre colonizadores e colonizados, significou o choque entre concepções de mundo distintas, como bem demonstraram as abordagens do pós-colonialismo e dos estudos subalternos. Igualmente importante é o reconhecimento de que, no interior do subcontinente, coexistiam inúmeras visões de mundo - relacionadas a grupos de castas, religiosos, linguísticos e tribais diversos -, sendo impossível falar na existência de um único universo simbólico indiano. $O$ encontro com os colonizadores propiciou e estimulou a reformulação de universos simbólicos tradicionais, sendo emblemático o processo de construção do hinduísmo como uma religião moderna, analisado e sintetizado por Oliveira (2014). A própria reação à dominação colonial envolveu a incorporação e a reinterpretação de discursos nacionalistas de matriz europeia, dinâmica que originou múltiplos projetos de nação, de acordo com Jaffrelot (2007), Khilnani (2004) e Zavos

\footnotetext{
${ }^{1}$ O Congresso Nacional Indiano, constituído a partir de 1885 como um centro de formação, discussão e expressão das ideias das novas classes políticas, compostas pelas elites nacionalistas indianas, continha em seu interior diversas correntes ideológicas. Eram membros do Congresso, então, partidários de projetos nacionalistas seculares e religiosos, em suas versões radicais e moderadas.

${ }^{2}$ Hindu Mahasabha, no original em híndi.
} 
(2001). Deve-se ter em mente, portanto, que o discurso nacionalista formulado por Savarkar apresentou e defendeu a realização de um projeto de nação específico, habitualmente denominado nacionalista hindu por promover a fusão de ideais nacionalistas e de concepções religiosas originárias de tradições bramânicas hindus.

É importante destacar, por fim, que não se tratava de um projeto nacionalista antibritânico. A Grande Associação Hindu colaborava sistematicamente com o governo colonial e não se opunha à permanência dos colonizadores desde que os interesses de grupos hindus de castas altas fossem reconhecidos e garantidos. Os outros do projeto nacionalista hindu eram as minorias religiosas, principalmente os muçulmanos indianos. Deve-se ressaltar, neste ponto, que o já mencionado encontro intercultural entre britânicos e indianos ocasionou, também, transformações nas relações entre os próprios habitantes do subcontinente. O aparato administrativo colonial requeria que as demandas relacionadas à distribuição de recursos fossem apresentadas por grupos sociais representados como comunidades - religiosas, linguísticas, de castas e tribais. Visto que o tamanho da comunidade seria levado em consideração nessas disputas, os grupos implicados definiam-se como comunidades majoritárias ou minoritárias. O processo de reconstrução de um universo simbólico hindu, orientado por concepções nacionalistas de matriz europeia, empreendido por ideólogos como Savarkar, insere-se, assim, no contexto de disputas por recursos entre uma comunidade majoritária hindu e comunidades minoritárias religiosas, principalmente muçulmanas, segundo as análises de Brass (2001), Thapar (1989) e Weiner (1997).

\section{Savarkar e a construção de um universo simbólico nacionalista hindu}

Hindutva. Who is a Hindu?, considerado o texto fundador do nacionalismo hindu contemporâneo, foi escrito por Savarkar durante seu período de reclusão e 
publicado em 1923, em Nagpur. Na obra em questão, o líder nacionalista hindu apresenta ao leitor - e à comunidade nacional indiana então em processo de formação - sua definição de identidade nacional-religiosa:

Hindu [...] é aquele que considera a terra que se estende de Sindhu a Sindhu - do Indo aos oceanos - como a terra de seus antepassados - sua Pátria (pitribhu); aquele que herda o sangue desta raça cuja origem remonta aos Saptasindhus Védicos ${ }^{3}$ e a qual, em sua marcha progressiva, assimilando muito do que foi incorporado e enobrecendo muito do que foi assimilado, passou a ser conhecida como o povo hindu; aquele que herdou e declara como sua a cultura desta raça, expressa principalmente por sua língua clássica comum, o sânscrito, e representada por uma história comum, uma literatura, arte e arquitetura, lei e jurisprudência, ritos e rituais, cerimônias e sacramentos, feiras e festivais comuns; e aquele que sobretudo trata esta terra, este Sindhusthan [Hindustão] como sua Terra Sagrada (punyabhu), como a terra de seus profetas e videntes, santos e gurus, a terra de devoção e peregrinação. Estes são os fundamentos de Hindutva - uma nação comum (rashtra), uma raça comum (jati) e uma civilização comum (sanskriti). Todos esses fundamentos poderiam ser mais bem sintetizados afirmando-se, em suma, que hindu é aquele para quem o Sindhusthan não é apenas pitribhu [pátria] mas também punyabhu [terra sagrada] (SAVARKAR, 2005, p. 115-116, tradução nossa).

A noção de hinduidade (Hindutva) apresentada por Savarkar em sua obra é uma concepção de identidade nacional-religiosa formulada por meio da incorporação e da reinterpretação de conceitos ocidentais presentes nas obras de autores como Johann Bluntschli, Herbert Spencer, Charles Darwin, Ernst Haeckel e Thomas Huxley. Analisar a influência das ideias de cada um desses autores sobre a obra de Savarkar foge aos objetivos deste artigo. No entanto, faz-se necessário reconhecer a importância desse corpo de teorias para a construção de uma identidade nacional caracterizada pela combinação de uma visão de mundo tradicional hindu com diferentes correntes teóricas ocidentais, como lembram Bhatt (2001) e Jaffrelot (1996).

\footnotetext{
${ }^{3}$ A expressão "Saptasindhus Védicos" refere-se ao epíteto que, segundo Savarkar, os árias teriam adotado quando chegaram à região dos Sete Rios (Saptasindhus) e que teria dado origem ao nome hindu.
} 
Segundo Savarkar, seriam três os fundamentos da hinduidade (Hindutva): uma nação (rashtra), uma raça (jati) e uma civilização (sanskriti) comuns. A nação seria definida segundo o critério geográfico. $O$ território da nação hindu - o Hindustão, país dos hindus - abrangeria todo o subcontinente indiano. Hindus seriam todos aqueles que nascessem em tal território, ou tivessem ancestrais originários do Hindustão, e que nutrissem um sentimento de pertença à pátria hindu. A hinduidade seria caracterizada, também, pelo critério racial. Os hindus constituiriam tanto uma nação, unida por laços de amor à pátria, como uma raça, vinculada por laços de sangue. Uma raça determinada por uma origem biológica comum, uma raça que carregaria o sangue dos antepassados védicos. Nesse sentido, um hindu não poderia perder seu Hindutva - embora pudesse perder sua casta ou seita - porque não poderia ser privado da herança do sangue hindu. Para o líder nacionalista hindu, os dois primeiros fundamentos, relacionados à noção de pátria (pitribhu), não seriam suficientes para definir a hinduidade. Considerar apenas critérios territoriais poderia dificultar a diferenciação entre os termos hindu e indiano. Uma vez que hindu seria todo aquele que habita o território indiano, a palavra hindu poderia significar um indiano, um cidadão do Hindustão, o que levaria a imprecisões como, por exemplo, denominar hindus grupos de muçulmanos residentes na Índia. $\mathrm{O}$ acréscimo do critério racial aos fundamentos da identidade hindu não eliminaria tais imprecisões. A maioria das comunidades cristãs e muçulmanas indianas, por exemplo, foram constituídas por hindus convertidos e, portanto, partilhariam da "ascendência védica", segundo Savarkar (2005).

A afirmação do ideólogo de que o critério territorial seria insuficiente para definir a pertença à nação hindu remete à oposição do nacionalismo hindu à concepção universalista de identidade nacional, construída por defensores de um projeto nacionalista secular. Segundo tal concepção, sustentada por líderes como Motilal Nehru e seu filho Jawaharlal Nehru, a pertença à nação indiana deveria ser definida exclusivamente de acordo com o critério territorial. Isso implicava o reconhecimento de que todos os cidadãos indianos - ou seja, todos aqueles que 
vivessem dentro das fronteiras da Índia britânica - seriam detentores de direitos iguais devido à sua condição de indivíduos e não de membros de um grupo específico (fosse religioso, linguístico, de casta ou tribal), de acordo com Jaffrelot (2007). Mas "Savarkar rejeitou qualquer forma de Estado-nação baseada num contrato social abstrato e que compreendesse, assim, cidadãos individualizados residindo no interior das fronteiras administrativas do país" (JAFFRELOT, 1996, p. 28, tradução nossa). Opôs-se ainda à concepção universalista de identidade nacional advogada por Gandhi, uma variante da formulada por Nehru. O líder da resistência passiva via a nação indiana como um conjunto de comunidades religiosas que se relacionavam, idealmente, de modo harmonioso e igualitário. Essa percepção, que tinha como referência um hinduísmo universalista e reformado, envolvia também o reconhecimento de que as diferentes identidades religiosas poderiam se expressar de modo legítimo na esfera pública, segundo Jaffrelot (2007). O ideólogo nacionalista hindu discordava de Gandhi e, por isso, Savarkar equiparava nação e comunidade majoritária hindu. Ademais, as relações entre a maioria hindu e as minorias religiosas - principalmente muçulmanas foram caracterizadas pelo ideólogo nacionalista hindu como relações predominantemente conflituosas, como se verá adiante.

Diante da percepção de que o critério territorial era insuficiente para definir a pertença à nação hindu, o líder nacionalista ressaltou a importância do terceiro fundamento da hinduidade: civilização. A despeito da aparente diversidade, os hindus seriam caracterizados por unidade cultural devido à sua história, literatura, arte e direito comuns. Além do mais, compartilhariam sanskaras - ritos e rituais, cerimônias e sacramentos -, ou seja, partilhariam do dharma hindu, o qual seria tão fortemente identificado com o Hindustão que este deveria ser considerado a terra sagrada (punyabhu) dos hindus. Assim, para Savarkar, o critério civilizacional ou cultural possuiria uma dimensão crucial para distinguir a hinduidade das identidades de outros grupos sociais habitantes do território indiano: a dimensão religiosa. Seria importante ressaltar, segundo o autor, que os 
termos hinduidade e hinduísmo são distintos. Hindutva seria uma concepção abrangente de nacionalidade, que compreenderia todas as áreas do pensamento e da atividade do povo hindu, inclusive seus aspectos religiosos. O hinduísmo seria, dessa forma, apenas uma parte da hinduidade: a fração correspondente à religião ou às religiões nativas do Hindustão. Para Savarkar, o hinduísmo poderia ser considerado a religião dos hindus - e constituir, assim, um aspecto importante da unidade cultural hindu -, desde que fosse concebido como um conjunto de sistemas de crenças diversas que incluísse tanto tradições védicas (que aceitam a autoridade dos Veda) como não védicas (que rejeitam a autoridade dos Veda). 4

Nessa acepção, hinduísmo e dharma hindu seriam expressões equivalentes e, a despeito de desempenharem um papel bastante específico e - de certo modo, limitado - na definição da identidade hindu, partilhariam necessariamente de todos os fundamentos de Hindutva: a) nação: o Hindustão seria o local de nascimento - a terra materna (matribhu) e paterna (pitribhu) - do dharma hindu; b) raça: assim como um hindu seria descendente de pais hindus, as diferentes tradições religiosas do povo hindu também seriam descendentes morais, culturais e espirituais do pensamento dos hindus védicos, os árias; c) civilização: a civilização hindu constituiria o ambiente cultural em que o dharma hindu se desenvolveu, especialmente no que se refere ao sânscrito e à mitologia e filosofia hindus. Dessa forma, para o autor, o Hindustão, devido a sua estreita ligação com o dharma hindu, seria inequivocamente a terra sagrada dos hindus, e o reconhecimento da sacralidade do território nacional seria requisito - e, deve-se ressaltar, elemento decisivo - para a definição da pertença à nação hindu e, por conseguinte, para a demarcação de fronteiras entre os hindus e os outros. Cristãos ou muçulmanos, por exemplo, não poderiam ser considerados hindus, uma vez que lhes seria impossível declarar o Hindustão como sua terra sagrada, embora pudessem reconhecê-lo como sua pátria, de acordo com Savarkar (2005).

\footnotetext{
${ }^{4}$ Savarkar (2005) menciona como tradições védicas: Sanatanan Dharma (referência ao movimento Sanatana Dharma) ou Shruti-smritipuranokta Dharma ou Dharma védico. Em se tratando de religiões ou tradições não védicas, refere-se a: Sikha Dharma (siquismo), Arya Dharma (menção ao movimento Arya Samaj), Jain Dharma (jainismo), Buddha Dharma (budismo).
} 
Em se tratando do critério cultural de pertença à nação hindu, Bhatt (2001) destaca que se observam tensões entre os aspectos religiosos e não religiosos da definição de hinduidade. Pode-se dizer que Savarkar procurou reduzir a importância do elemento religioso para a demarcação da identidade hindu, ao afirmar que o hinduísmo era apenas um aspecto do critério cultural da identidade em questão. Isso pode ser associado, por um lado, à tentativa de lidar com a grande diversidade religiosa característica da sociedade indiana - a qual dificultava a representação de uma comunidade hindu homogênea. Por outro lado, relaciona-se à incorporação, pelo ideólogo, da noção orientalista de que o hinduísmo era uma civilização arcaica e não propriamente uma religião, como argumentam Bhatt (2001) e Jaffrelot (1996). É importante destacar, ainda, que o aspecto religioso da hinduidade está estreitamente relacionado à descrição moderna do hinduísmo como uma religião essencialmente bramânica que reúne, de modo paternalista, diferentes seitas védicas e não védicas, bem como grupos de castas altas, de castas baixas e de intocáveis, de acordo com Thapar (1989). Entretanto, não se pode desconsiderar que o critério religioso se tornou decisivo no discurso de Savarkar para a delimitação de fronteiras entre os hindus e os outros, tema discutido em maiores detalhes na próxima seção.

\section{Retórica de aniquilação no discurso sobre a nação hindu e o outro}

É interessante observar como o discurso sobre a hinduidade e a nação hindu, tal como elaborado por Savarkar, é predominantemente um discurso sobre a pertença à nação. Trata-se, nesse sentido, de um esforço de delimitação de fronteiras entre grupos formuladores de universos simbólicos distintos - nesse caso, hindus e muçulmanos. Contudo, à semelhança do que fizeram líderes nacionalistas hindus contemporâneos, o ideólogo em questão não se ocupou da análise e/ou da crítica do conteúdo da concepção de mundo do outro, o muçulmano. Desse modo, a formulação de uma retórica de aniquilação por 
Savarkar baseou-se, em primeiro lugar, no recurso de transferência de definições negativas ao grupo externo como tal - sem considerações sobre o que de fato significaria o islã, de modo geral, e o islã praticado na Índia, de modo específico. Concentrou-se na caracterização dos muçulmanos indianos como inferiores, a princípio, e como não pertencentes ao grupo interno, a nação hindu, em última instância. Em segundo lugar, tal retórica fundamentou-se no recurso de exagero seletivo de: i) características atribuídas ao outro - como intolerância e agressividade, por exemplo; ii) certos aspectos da relação entre hindus e muçulmanos, de modo a ressaltar seu caráter conflituoso. Os dois recursos retóricos empregados por Savarkar serão examinados em detalhes nas subseções seguintes.

\subsection{Transferência de definições negativas às comunidades muçulmanas indianas}

Descritos em várias passagens da obra de Savarkar como ameaçadores, intolerantes e agressivos, os "invasores muçulmanos" foram por ele considerados inferiores aos hindus. Tal inferioridade foi compreendida pelo ideólogo segundo os critérios culturais e raciais analisados na seção anterior. Em termos culturais, se os hindus eram caracterizados pela pertença a uma civilização - que compreendia, ainda, uma nação e uma raça -, a identidade do grupo minoritário muçulmano seria definida pela afiliação a uma religião ou ideologia - o islã -, aspecto limitado da concepção mais ampla de civilização, tal como entendida pelo líder nacionalista. Nesse sentido, os outros da nação hindu seriam inferiores devido a sua condição de bárbaros (mleccha), de estrangeiros incivilizados, segundo Bhatt (2001).

A caracterização de muçulmanos indianos como estrangeiros remete ao argumento de Savarkar de que haveria, no subcontinente, grupos de origem hindu em posições intermediárias entre as condições de nacional e de estrangeiro. Os muçulmanos indianos seriam hindus vítimas de conversões forçadas a uma religião não hindu, o islã. Eles partilhariam de quase todos os fundamentos da hinduidade, mas se comportariam como estrangeiros em muitas situações porque, 
ao decidirem permanecer vinculados à religião de conversão, teriam dividido sua lealdade entre a pátria - o Hindustão - e a terra sagrada - Meca, como afirma Savarkar (2005). Não poderiam, assim, ser considerados membros da comunidade nacional hindu, uma vez que a hinduidade requeria o reconhecimento do Hindustão não apenas como pátria, mas também como terra sagrada. Ademais, a construção e/ou manutenção de lealdades transnacionais por indianos muçulmanos foram compreendidas como deslealdade e vistas, por isso, como uma ameaça à integridade - territorial ou cultural - da nação hindu, segundo Bhatt (2001) e Jaffrelot (1996).

No que se refere ao critério racial apresentado por Savarkar, é importante destacar que o princípio biológico de pertença à nação hindu - ascendência - está estreitamente relacionado a aspectos culturais cruciais para a compreensão da ideia de raça defendida pelo autor: relações de alteridade orientadas pelo caráter inclusivo do hinduísmo e pela ordem social hierárquica do sistema de castas, de acordo com Jaffrelot (1996). Quando se tem por referência o pensamento religioso clássico, as principais características da sociedade indiana são a resistência e a persistência de estilo e padrões, que estão relacionadas à capacidade de "incluir outras culturas e de possibilitar que muitos níveis de civilização vivam lado a lado" (EMBREE, 1990, p. 25, tradução nossa). Tais características remetem a cinco pressupostos do pensamento religioso indiano. O primeiro deles é a concepção de tempo cíclico, segundo a qual existem ciclos de longuíssima duração que se repetem indefinidamente no tempo. O segundo pressuposto está vinculado ao conceito de karman (ação), à crença em uma lei natural que postula que toda ação gera necessariamente uma consequência apropriada, que se manifesta em algum ponto de uma cadeia infinita de existências (ciclos de tempo eternamente repetitivos). Daí a crença na reencarnação ou renascimento, o terceiro pressuposto, que está associado não apenas ao karman, mas, ainda, ao dharma, o quarto pressuposto. As obrigações de cada indivíduo são determinadas por sua posição social, a qual, por sua vez, é determinada pelo nascimento (jati). O quinto 
pressuposto é o de que, embora exista apenas uma verdade, há muitos níveis de verdade. Em última instância, o acesso à verdade é desigual, uma vez que se rejeita a ideia de que todas as pessoas sejam capazes de compreender a realidade da mesma forma. Práticas religiosas específicas são consideradas verdadeiras para aqueles que nelas acreditam e, visto que existem muitos níveis de verdade, "todas as práticas sociais podem ser incluídas no interior da sociedade, contanto que haja disposição para aceitar as premissas da inclusão" (EMBREE, 1990, p. 30, tradução nossa).

Deve-se ressaltar que, no discurso sobre a hinduidade e a nação hindu, as premissas para inclusão de grupos minoritários estão estreitamente vinculadas às relações hierárquicas estabelecidas pelo sistema de castas. A tradução de jati (nascimento) como raça por Savarkar estabelece uma relação imediata entre posição no interior do sistema de castas e raça. Isso quer dizer que não apenas a raça hindu seria organizada hierarquicamente, mas, ainda, que outras "raças" minoritárias - deveriam se relacionar com os hindus segundo os critérios do sistema de castas: deveriam ser assimiladas, integradas a níveis subordinados da ordem hierárquica hindu. Mesmo a reintegração 5 de grupos formados por pessoas de origem hindu, ${ }^{6}$ como os muçulmanos indianos, deveria obedecer a essa lógica de inclusão por subordinação, segundo Jaffrelot (1996). Aos islamitas caberia, portanto, uma posição inferior dentro do sistema de estratificação social representado pelas castas.

É importante destacar, neste ponto, que a maioria dos muçulmanos indianos é descendente de hindus de castas baixas ou de intocáveis que se converteram ao islã. Apenas uma minoria descende de colonos e invasores árabes, iranianos ou provenientes da Ásia Central. Durante o período de dominação muçulmana na Índia, os muçulmanos nobres, de ascendência não indiana, e os

\footnotetext{
${ }^{5}$ Trata-se, nesse caso, da possibilidade de realizar a reconversão de cristãos e muçulmanos ao hinduísmo, instituída pela prática de shuddhi (purificação). As cerimônias de purificação e reconversão de indivíduos das minorias religiosas consideradas podem ser associadas à terapêutica, na medida em que buscam promover sua reintegração à concepção de mundo do grupo interno.

${ }^{6}$ Deve-se ressaltar que se utilizou aqui a terminologia adotada por Savarkar. Mais preciso seria dizer pessoas de origem indiana, tendo em vista a grande diversidade religiosa do subcontinente. É importante destacar, mais uma vez, que o termo indiano, referente à nacionalidade, não é equivalente a hindu, relacionado à pertença a tradições religiosas específicas.
} 
conversos hindus de castas altas desempenharam um papel-chave na administração do Estado como conselheiros, ministros, governadores, oficiais do exército etc. Mas a base, composta de indianos convertidos, a maioria da população muçulmana, permaneceu ligada às ocupações tradicionais (artesãos e camponeses, por exemplo), organizou-se em estratos sociais semelhantes às castas hindus e compartilhou da condição de pobreza das castas mais baixas, como lembra Sikand (2001). Dessa forma, o argumento do líder nacionalista hindu sobre a manutenção de uma posição subordinada das minorias religiosas, de modo geral, e da minoria muçulmana, de modo específico, buscava não apenas justificar a presença de muçulmanos indianos entre as camadas sociais mais baixas mas, ainda, obstruir quaisquer possibilidades de ascensão social dessa minoria religiosa, criadas por políticas de ação afirmativa então adotadas pelo governo colonial britânico.

\subsection{Exagero seletivo de características atribuídas às comunidades muçulmanas indianas e a suas relações com a comunidade majoritária hindu}

A descrição da nação como uma entidade primordial é uma das faces paradoxais do nacionalismo. Embora sejam relativamente recentes, as nações, conforme apresentadas nos discursos nacionalistas, afirmam ter suas raízes num passado remoto. Não bastasse isso, negam serem construções sociais. Apresentamse como “naturais' o bastante para não necessitarem de definições que não a defesa dos próprios interesses" (HOBSBAWM, 1984, p. 22). Entretanto, a prática de reescrever a história, de modo a enfatizar a primordialidade da nação, constitui uma das estratégias mais frequentemente adotadas por ideólogos nacionalistas. Battacharya (2003) argumenta que, apesar de integrar um processo mais amplo de desenvolvimento do conhecimento histórico - por meio da constante seleção, leitura, representação, interpretação e narração de eventos -, a reescrita da história é por vezes empregada na formulação de projetos políticos de caráter violento e agressivo contra minorias, como é o caso do discurso nacionalista hindu. 
Em se tratando do discurso elaborado por Savarkar, mais especificamente, a estratégia de reescrita da história fundamentou a seleção e a exageração de aspectos particulares das relações entre hindus e muçulmanos.

Para o ideólogo, a história do povo hindu seria uma história de guerra e migração. A periodização da história hindu realizada por Savarkar remete ao contato e, principalmente, ao conflito com outros povos. A formação e o fortalecimento do universo simbólico nacional-religioso hindu, caracterizado pelo líder nacionalista simplesmente como uma concepção de mundo hindu, teriam ocorrido por meio de períodos sucessivos de colonização, expansão territorial e invasão. A elaboração da narrativa sobre a nação hindu nesses termos, por Savarkar, está relacionada à apropriação por ele realizada de duas concepções orientalistas formuladas no século 19.

A primeira delas foi a percepção de que o hinduísmo era caracterizado por uma imobilidade ensimesmada. Tratar-se-ia de uma religião imutável, desprovida de historicidade na ausência de ameaças externas. Elemento extrínseco à sociedade hindu, a história da nação hindu seria colocada em movimento apenas por meio de processos de migração e conflito - na forma de guerras, conquistas e invasões, de acordo com Bhatt (2001). Nesse sentido, a própria concepção de história adotada pelo líder nacionalista hindu pressupunha o conflito com o outro. O ideólogo reconheceu que o contato com o outro teria permeado toda a história da nação hindu e apresentado formas ordinárias - relações comerciais e diplomáticas, principalmente, que originariam movimentos tanto de emigração como de imigração - e extraordinárias - invasões estrangeiras. No entanto, para Savarkar (2005), as formas extraordinárias, caracterizadas por relações conflituosas com o estrangeiro (mleccha) no território indiano, é que constituiriam acontecimentos decisivos para o fortalecimento da hinduidade.

A segunda noção orientalista incorporada pelo ideólogo nacionalista hindu foi a visão religiosa da sociedade indiana. Trata-se da caracterização de processos sociais complexos - como tensões sociais, disputas políticas ou diferenças culturais 
- em termos predominantemente religiosos, que alude à introdução do padrão de periodização religiosa da história indiana por James Mill. Segundo essa perspectiva, haveria, na história indiana, sucessivos períodos marcados pela predominância de determinada prática religiosa, devido a sua ligação com os governantes do Estado: períodos hindu, budista e muçulmano, por exemplo, como argumentam Pannikar (2000) e Searle-Chatterjee (2000). A própria periodização religiosa da história incorporada no discurso de Savarkar constitui uma exageração da importância das identidades religiosas para caracterizar e compreender as relações sociais no interior do subcontinente ao longo da história. Relações sociais de caráter econômico e político foram excluídas das narrativas influenciadas por tal visão religiosa do passado. Além disso, dinâmicas referentes a relações de cooperação entre os demais grupos religiosos (ou, ainda, ao sincretismo religioso), assim como processos relacionados às interações entre os diversos grupos de castas, linguísticos e tribais, coexistentes em cada um dos períodos, foram negligenciados.

Para Savarkar, a história do povo hindu seria composta pelos períodos védico, budista, hindu e muçulmano. À exceção do período hindu, que teria durado um milênio, a partir do início da Era Comum, todos os demais teriam sido iniciados por conquistas externas - consideradas benignas, como no caso da colonização ária do subcontinente,7 ou malignas, como as invasões budista ${ }^{8}$ e muçulmana, por exemplo. Não há, em sua obra, nenhuma menção a um período cristão, caracterizado pela dominação britânica, o que remete à recusa em construir um discurso ou projeto nacionalista antibritânico, tema discutido

\footnotetext{
${ }^{7}$ De acordo com o ideólogo, a ocupação ária do território do Hindustão, evento fundador da nação hindu, teria sido marcada por uma convivência amistosa com a população local, o que se deveria à amabilidade e à benevolência dos nativos - que, por exemplo, teriam sido guias dos colonizadores em sua exploração do território que adotariam como nova pátria -, bem como à grandeza da missão civilizadora a que estariam destinados os árias. O termo colonização apresentaria, assim, uma conotação positiva no discurso de Savarkar (2005).

${ }^{8}$ Savarkar (2005) se refere a shakas e hunos, descritos por ele como hordas de bárbaros com inclinações budistas. A invasão dos shakas - grupos originários da Ásia Central que tomaram o noroeste do que atualmente constitui o território indiano - ocorreu por volta do século 1 A.E.C., coincidindo com o declínio dos reinos gregos nessa região. Os hunos, por sua vez, derrotaram a dinastia Gupta no século 4 E.C. - após sucessivos ataques ao norte do subcontinente, entre os séculos 4 e 5 E.C. - e anexaram parte do território indiano ao seu reino, que se estendia da Pérsia (atual Irã) a Hotan (China), de acordo com Thapar (1990).
} 
anteriormente. Para os fins deste artigo, interessa analisar o discurso do ideólogo nacionalista hindu sobre o período muçulmano.

Após cerca de mil anos de soberania hindu, predominantemente harmônicos, o florescimento da nação hindu teria sido interrompido por invasões muçulmanas. Um conflito mortal, prolongado e furioso, entre hindus e muçulmanos, ter-se-ia iniciado quando as "hordas invasoras", lideradas por Mohammed de Gazni, 9 cruzaram o rio Indo e penetraram no Hindustão. Segundo o autor, as vítimas hindus se encontravam em condições extremamente desfavoráveis devido à superioridade numérica dos conquistadores - o islã teria dominado quase todo o continente asiático, abarcando, assim, povos tão diversos como árabes, persas, tártaros, turcos e mogóis. ${ }^{10}$ Tratar-se-ia do confronto entre uma nação, a nação hindu, e uma unidade político-religiosa de dimensões continentais, o islã. A despeito da desigualdade de condições, os hindus teriam resistido bravamente à dominação muçulmana. Ao fazê-lo, teriam atingido o ápice da unidade e da autoconsciência hindus. Isso porque, segundo o líder nacionalista hindu, "não há nada como um conflito com o outro para tornar o eu mais consciente de si mesmo. Não há nada como a pressão de um inimigo comum para unificar povos em uma nação e unificar nações em um Estado” (SAVARKAR, 2005, p. 42, tradução nossa).

Deve-se atentar para o fato de que as invasões estrangeiras inauguraram, no discurso de Savarkar, períodos religiosos caracterizados pela vitimização hindu, principalmente no que se refere ao período muçulmano. De acordo com Bhatt (2001), trata-se de uma estratégia retórica que pretendia apresentar uma história de inocência e opressão da nação hindu, assim como afirmar que a força motora da história era o vigor e o poder da hinduidade. Bastante influente, nesse caso, foi o recurso de exageração, em primeiro lugar, da superioridade bélica e numérica dos conquistadores - de acordo com o ideólogo, teria havido o confronto entre

\footnotetext{
${ }^{9}$ Ao longo das três primeiras décadas do século 11, o soberano do principado de Gazni (no atual Afeganistão), realizou várias incursões pelo subcontinente indiano, segundo Thapar (1990).

${ }^{10}$ Mogul ou Mughal: referência aos imperadores muçulmanos de Déli, dos séculos XVI ao XIX.
} 
uma nação, hindu, e um continente, muçulmano; em segundo lugar, da intolerância e agressividade dos governantes muçulmanos que se estabeleceram no Norte da Índia, assim como da população muçulmana, de modo geral. A despeito da violência dos processos de conquista, não se deve esquecer a existência de governantes islâmicos como Akbar, o terceiro imperador mogol, que prezou pelo diálogo inter-religioso. Ademais, é importante lembrar a coexistência pacífica entre grupos hindus e muçulmanos e, também, o surgimento de tradições sincréticas como o sufismo indiano, que atraiu, ao longo dos séculos, tanto fiéis islamitas como devotos hindus.

Por fim, Savarkar (2005) declarou que nem todos os estrangeiros seriam considerados inimigos. Contudo, seriam essencialmente diferentes dos hindus e, por isso, teriam sua identidade definida em oposição ao Hindutva. Os estrangeiros habitariam um território diferente, o Mlecchasthan (terra dos estrangeiros), concebido em oposição ao Hindustão, um Estado composto pelo território e pela nação dos hindus e caracterizado por instituições tão peculiares como o sistema de quatro varna. ${ }^{11}$ Além disso, tais estrangeiros seriam originários de uma raça diferente e teriam uma cultura diferente, o que, deve-se ressaltar, implicaria lealdade a uma terra sagrada distinta. De acordo com essa perspectiva, os invasores muçulmanos seriam estrangeiros na acepção da palavra. Seriam, ainda, inimigos da nação hindu, fosse por sua intolerância e agressividade, fosse por sua lealdade a uma religião semítica, também ela estrangeira e conquistadora.

\footnotetext{
${ }^{11}$ Varna (cor) se aproxima da concepção ocidental de status e não era determinado por nascimento. A palavra que geralmente se traduz por casta é jati, a qual remete à concepção de que a pertença à hierarquia social era determinada por nascimento.
} 


\section{Conclusão}

Conforme mencionado na introdução deste artigo, a transformação de uma retórica de aniquilação em práticas de violência contra grupos externos depende da disponibilidade de recursos de poder aos participantes das relações consideradas. É interessante observar como, no discurso elaborado por Savarkar a respeito da nação hindu e de seu outro, grupos sociais originários do subcontinente indiano são retratados como grupos externos à comunidade cultural. Na obra Hindutva. Who is a Hindu?, o ideólogo nacionalista preocupouse com a delimitação de fronteiras entre hindus e muçulmanos, assim como ressaltou o caráter conflituoso das relações entre as duas comunidades religiosas. Mas o autor ali não defendeu explicitamente a agressão a muçulmanos indianos.

A caracterização dos islamitas como estrangeiros, realizada por Savarkar, seria retomada, contudo, por ideólogos nacionalistas hindus contemporâneos com a finalidade de justificar e incitar atos violentos contra essa minoria religiosa. Em períodos de instabilidade política, fragilidade do controle estatal e fortalecimento da capacidade de mobilização das massas por parte de organizações nacionalistasreligiosas - quando da Partição do subcontinente em dois Estados-nação distintos, Índia e Paquistão, no final da década de 1940, e dos conflitos entre hindus e muçulmanos envolvendo a disputa por uma estrutura religiosa no Norte da Índia, na década de 1990, por exemplo -, os partidários da construção de um Estadonação hindu valeram-se dos recursos de poder disponíveis para tentar concretizar seus ideais, ainda que isso significasse exterminar os outros da nação hindu.

Tendo em vista as inúmeras ocorrências de vinculação de uma retórica de aniquilação a práticas violentas contra minorias religiosas na Índia contemporânea, pode-se afirmar a importância de se conhecer e analisar a retórica de aniquilação construída por Savarkar ainda na década de 1920. Igualmente relevante é o reconhecimento de que tal retórica foi apropriada e reinterpretada por seguidores e admiradores de Savarkar, de modo a formar uma das principais 
correntes políticas da Índia contemporânea: o nacionalismo hindu de organizações paramilitares como a Organização Nacional de Voluntários (Rashtriya Swayamsevak Sangh, RSS), de grupos político-religiosos como o Conselho Mundial Hindu (Vishwa Hindu Parishad, VHP) e de partidos políticos como o Partido do Povo Indiano (Bharatiya Janata Party, BJP).

\section{REFERÊNCIAS}

BATTACHARYA, N. The problem: Rewriting history, a symposium on ways of representing our shared past. Seminar, n. 522, Feb. 2003. Disponível em: <www.indiaseminar.com> Acesso em: 17 set. 2006.

BERGER. P. L.; LUCKMANN, T. A construção social da realidade. Petrópolis: Vozes, 2003.

BHATT, C. Hindu Nationalism: origins, ideologies and modern myths. London: Berg Publishers, 2001.

BRASS, P. R. The politics of India since independence. New York: Cambridge University Press, 2001.

EMBREE, A. T. Utopias in conflict. Religion and nationalism in modern India. Berkeley, Los Angeles: University of California Press, 1990.

HOBSBAWM, E. Introdução: A Invenção das tradições. In: HOBSBAWM, E.; RANGER, T. A invenção das tradições. Rio de Janeiro: Paz e Terra, 1984.

JAFFRELOT, C. The Hindu nationalist movement in India. New York: Columbia University Press, 1996.

JAFFRELOT. Introduction: The invention of an ethnic nationalism. In: JAFFRELOT (Ed.). Hindu Nationalism. A Reader. New Jersey: Princeton University Press, 2007. p. 3-25.

KHILNANI, S. The Idea of India. New Delhi: Penguin Books India, 2004.

OLIVEIRA, M. S. R. Identidade e religião hindus na Índia britânica. Revista de Estudos da Religião, São Paulo, ano 14, n. 1, p. 152-178, 2014. 
PANNIKAR, K. N. Outsider as enemy: the politics of rewriting history in India. Columbia International Affairs Online, Columbia, November 2000. Disponível em:

<http://www.ciaonet.org/frame/wpsfrm.html> Acesso em: o9 abr. 2003.

SAVARKAR, V. D. Hindutva: who is a Hindu? $6^{\text {th }}$ edn. Delhi: Hindi Sahitya Sadan, 2005.

SEARLE-CHATTERJEE, M. 'World religions' and 'ethnic groups': do these paradigms lend themselves to the cause of Hindu nationalism? Ethnic \& Racial Studies, London, v. 23, n. 3, p. 497-515, May 2000.

SIKAND, Y. A New Indian Muslim Agenda: The Dalit Muslims and the All-India Backward Muslim Morcha. Journal of Muslim Minority Affairs, New Delhi, v. 21, n. 2, p. 287296, Oct. 2001.

THAPAR, R. Immagined religious communities? Ancient history and the modern search for a Hindu identity. Modern Asian Studies, [S.I.], v. 23, n. 2, p. 209-231, 1989.

THAPAR, R. A History of India. London: Penguin Books, 1990, v.1.

USARSKI, F. A retórica de “aniquilação”. Uma reflexão paradigmática sobre recursos de rejeição a alternativas religiosas. Revista de Estudos da Religião, São Paulo, n.1, p. 91111, 2001.

WEINER, M. Minority identities. In: KAVIRAJ, S. (Ed.). Politics in India. New Delhi: Oxford University Press, 1997, p. 241-253.

ZAVOS, J. Defending Hindu tradition: Sanatana Dharma as a symbol of orthodoxy in colonial India. Religion, [S.1], n. 31, p.109-203, 2001. 